\title{
PENGARUH PENERAPAN METODE MODELING THE WAY TERHADAP HASIL BELAJAR KETERAMPILAN MENYUSUN PARAGRAF BAHASA INDONESIA MURID KELAS III SDN 7 LETTA KECAMATAN BANTAENG KABUPATEN BANTAENG
}

\author{
Ayu Fitriani, Aliem Bahri \\ Pendidikan Guru Sekolah Dasar, Fakultas Keguruan dan Ilmu Pendidikan \\ Universitas Muhammadiyah Makassar \\ Aliem_bahri@yahoo.co.id
}

\begin{abstract}
ABSTRAK
Penelitian ini bertujuan untuk mengetahui pengaruh penerapan modeling the way terhadap hasil belajar keterampilan menyusun paragraf bahasa indonesia murid Kelas III SDN 7 Letta kecamatan bantaeng kabupaten bantaeng. Jenis penelitian ini merupakan penelitian kuantitatif model eksperimen menggunakan desain Pre-Eksperimental dengan bentuk One Group PretestPosttest Design. Sampel penelitian ini adalah murid Kelas III SDN 7 Letta Kecamatan Bantaeng Kabupaten Bantaeng yang berjumlah 10 murid. Data dikumpulkan menggunakan observasi, tes dan dokumentasi, sedangkan data hasil penelitian dianalisis secara deskriptif dan inferensial dengan uji t. Berdasarkan rata-rata hasil posttest diperoleh rata-rata posttest keterampilan Menyusun paragraf pribadi murid setelah diterapkan modeling the way lebih tinggi dibandingkan dengan rata-rata hasil pretest sebelum diterapkan metode modeling the way. Rata-rata pretest yang diperoleh sebelum diterapkan metode modeling the way yaitu 60,8. Setelah dilakukan tindakan dengan perlakuan model modeling the way, maka diperoleh ratarata nilai posttest yaitu 81,7. Jumlah peningkatan kelas berdasarkan nilai pretest dan posttest sebesar 19,94\%. Pengujian hipotesis dilakukan dengan menggunakan uji t, menunjukkan bahwa nilai $t_{\text {hitung }}=19,79755$ dengan db sebesar $10-1=9$ pada taraf signifikasi 0,05 diperoleh $t_{\text {tabel }}=$ 2,262 sehingga diperoleh $\mathrm{t}_{\text {hitung }}<\mathrm{t}_{\text {tabel. }}$. maka disimpulkan $\mathrm{H}_{0}$ ditolak $\mathrm{H}_{1}$ diterima yang berarti bahwa. penerapan model modeling the way berpengaruh terhadap keterampilan menulis surat pribadi murid Kelas III SDN 7 Letta Kecamatan Bantaeng Kabupaten Bantaeng.
\end{abstract}

Kata kunci : metode modeling the way, hasil belajar keterampilan menyusun paragraf 


\section{PENDAHULUAN}

Proses pembelajaran adalah kegiatan yang bernilai edukatif, nilai edukatif tersebut mewarnai interaksi yang terjadi antara guru dengan murid, murid dengan murid, murid dengan sumber balajar dalam mencapai tujuan pembelajaran. Kegiatan belajar mengandung komponen. Komponen yang saling tergantung satu sama lain untuk mencapai tujuan. Suatu sistem belajar mengajar memuat berbagai komponen, antara lain tujuan, bahanbahan, murid, guru, metode, situasi, dan evaluasi. Agar tujuan itu tercapai semua komponen yang harus di organisasikan sehingga antar sesama komponen terjadi kerjasama.

Harapan pada setiap guru adalah bagaimana materi pelajaran yang disampaikan kepada anak didiknya dapat diterima dan dipahami secara tuntas. Untuk memenuhi harapan tersebut bukanlah sesuatu yang mudah, karena kita sadar bahwa setiap murid memiliki karakteristik yang tidak sama baik dari segi minat, potensi, kecerdasan dan usaha murid itu sendiri. Dalam proses belajar mengajar kemampuan berpikir murid berbeda-beda ada yang lambat dan ada yang cepat sehingga dalam proses pembelajaran masih dominan murid yang pintar. Untuk mencapai harapan dan memecahkan persoalan tersebut, guru dapat mengembangkan teknik pembelajaran dengan modeling the way sehingga pembelajaran ini dapat membuat murid menjadi aktif dan menyenangkan serta memberikan semangat dalam berpikir dan belajar. Pembelajaran yang baik adalah pembelajaran yang bisa membawa rasa senang kepada murid sehingga membuat mereka asyik belajar. Dengan harapan pemahaman murid mampu meningkatkan hasil belajar atau prestasi murid.

Dalam proses belajar mengajar kemampuan belajar dan berfikir murid berbeda-beda ada yang lambat dan ada yang cepat sehingga dalam proses pembelajaran masih didominan oleh murid yang pintar. Apalagi dalam pembelajaran Bahasa Indonesia, tidak semua murid lancar membaca dan menulis. Karena pokok materi dan target utama selain pengolahan materi untuk murid kelas III adalah bagaimana anak didik bisa lancar membaca dan menyusun paragraf dengan benar. Untuk mencapai harapan dan memecahkan persoalan tersebut, guru dapat mengembangkan teknik pembelajaran dengan menggunakan modeling the way. Model modeling the way merupakan model yang cukup menyenangkan yang digunakan untuk mengulang materi yang telah diberikan sebelumnya. Dengan demikian, materi 
baru pun tetap bisa diajarkan dengan model ini dengan catatan, peserta didik diberi tugas mempelajari topik yang akan diajarkan terlebih dahulu, sehingga ketika masuk kelas mereka sudah memiliki bekal pengetahuan. modeling the way tidak hanya digunakan dalam mata pelajaran Bahasa Indonesia saja, tetapi dapat digunakan dalam mata pelajaran yang lainnya. Dengan model ini siswa akan lebih aktif dan semua siswa ikut terlibat dalam pembelajaran.

Sehingga pembelajaran ini dapat membuat murid aktif bukan saja aktif secara fisik tetapi juga aktif psikisnya dan saling berinteraksi antar murid dengan murid lainnya, murid dengan guru dan sumber belajar sehingga murid lebih percaya diri. Metode pembelajaran ini penulis rancang dengan memberikan ilustrasi dan demontasi pada murid untuk mencari, menemukan, memutuskan, dan menyusun paragraf jawaban secara individual kemudian didiskusikan bersama dengan teman lainnya dalam kelas. Guru sebagai fasilitator yang bertugas membimbing dan mengarahkan murid dalam proses belajar mengajar. Metode pembelajaran ini juga memberikan kebebasan dalam menggunakan gagasan, jawaban yang tepat. Metode ini juga berfungsi mengubah pola pembelajaran konvensional yang seluruh rangkaian belajar mengajar berpusat pada guru tanpa memberikan kesempatan pada murid sehingga kadang-kadang murid terbelenggu oleh aturan dan penggunaan strategi yang monoton dan membosankan sehingga anak didik menjadi anak yang penakut.

Metode pembelajaran modeling the way dimungkinkan mampu membuat peserta didik untuk dapat belajar dengan mudah, menyenangkan dan dapat tercapai tujuan pembelajaran sesuai dengan tuntutan kompetensi. Pembelajaran Bahasa Indonesia secara umum diarahkan untuk meningkatkan kemampuan peserta didik untuk berkomunikasi dalam Bahasa Indonesia dengan baik dan benar, baik secara lisan maupun tulisan, serta menumbuhkan apresiasi terhadap hasil karya kesastraan manusia Indonesia. Selain itu, melalui pembelajaran Bahasa Indonesia diharapkan mampu menumbuhkan sikap murid untuk menghargai dan membanggakan, serta mencintai Bahasa Indonesia sebagai bahasa persatuan (nasional) dan bahasa negara.

Dari uraian di atas mendorong penulis untuk melakuakan penelitian tentang adakah dorongan orang tua dengan pendidikan anak yang diterima dari orangorang sekitar, sehingga anak termotivasi untuk belajar lebih rajin dan percaya diri 
dengan kemampuan yang dimiliki dirinya sehingga hasil belajarnya meningkat dengan judul "Pengaruh Penerapan Metode Modeling The Way Terhadap Hasil Belajar Keterampilan Menyusun Paragraf Bahasa Indonesia Murid kelas III SDN 7 Letta Kecamatan Bantaeng Kabupaten Bantaeng".

\section{Kajian literatur}

Ari Fajarwati (2009) dalam penelitiannya yang berjudul Upaya Peningkatan Keaktifan dan Minat Murid dalam Pembelajaran Bahasa Indonesia melalui model Modeling the way (Mencari Pasangan). Membuktikan pembelajaran matematika pada pokok bahasan keliling dan luas bangun segi empat menggunakan strategi Modeling the way yang membuktikan tingkat keaktifan dan minat murid dalam proses pembelajaran dan bertanya kepada guru dan kepada temannya, peningkatan dari 1 murid $(2,63 \%) \quad$ menjadi 27 siswa (71,05\%). Berdasarkan hasil penelitian tindakan di atas dapat disimpulkan bahwa Modeling the way yang termasuk metode pembelajaran active learning merupakan salah satu faktor yang sangat berperan dalam meningkatkan keaktifan belajar pada murid. Oleh karena itu, sangat beralasan diadakan penelitian tindakan mengenai penerapan strategi pembelajaran Modeling the way dalam meningkatkan keaktifan murid.

$$
\text { Parjiati (2009) dalam }
$$

penelitiannya yang berjudul Pendekatan Terpadu dalam Pembelajaran Bahasa Indonesia untuk Meningkatkan Keterampilan Menulis membahas tentang pembelajaran bahasa Indonesia dengan pendekatan terpadu. Pendekatan ini memadukan empat keterampilan berbahasa meliputi menyimak, berbicara, membaca, dan menulis. Dalam satu kesatuan kegiatan yang tidak terpisahkan. Namun bila dicermati, penelitian ini mengkaji keterampilan menulis lanjutan pada murid kelas III Sekolah Dasar yang disatukan dengan keterampilan membaca, yaitu tentang meringkas cerita.

Sri Lestari (2009) dalam penelitiannya yang berjudul Upaya Meningkatkan Keterampilan Menulis Murid Dengan Pendekatan Kontekstual Pada Murid Kelas III SD Negeri 4 Gunungan Kabupaten Wonogiri. Penelitian ini bertujuan untuk meningkatkan minat dan keterampilan menulis murid dengan pendekatan kontekstual. Penelitian ini merupakan Penelitian Tindakan Kelas yang mengambil lokasi dikelas III SDN 7 Letta 
Kecamatan Banteng Kabupaten Banteng. Penelitian ini dilaksanakan dalam tiga siklus. Rencana Pembelajaran setiap siklus disusun oleh guru dan peneliti. Setiap tindakan terdiri dari empat tahap, yaitu perencanaan, tindakan, pengamatan, dan refleksi. Hasil refleksi dijadikan dasar untuk menyusun rencana tindakan.

Penelitian melakukan bimbingan intensif kepada guru kelas III tentang penerapan pendekatan kontekstual dalam pembelajaran untuk meningkatkan keterampilan menulis murid kelas III yang masih rendah. Penelitian ini dapat dikatakan penelitian tindakan kelas secara kolaboratif. Yang menjadi subjek penelitian ini adalah seluruh murid kelas III SDN 7 Letta dan guru kelas III. Data yang dikumpulkan berupa minat dan keterampilan menulis murid kelas III. Teknik pengumpulan data yang digunakan adalah angket, pengamatan, wawancara atau diskusi, kajian dokumen, dan tes. Uji validitas data dalam penelitian ini dengan triangulasi dan review informan kunci. Data yang telah terkumpul dianalisis dengan tehnik analisis kritis dan analisis komparatif. Hasil penelitian dapat disimpulkan sebagai berikut: Pertama, penerapan pendekatan kontekstual dapat meningkatkan minat menulis murid, hal itu terlihat bahwa setelah dilakukan tindakan murid membuat perencanaan sebelum menulis, merevisi setelah menyeleksi tulisan, menggunakan Pedoman Ejaan Bahasa Indonesia (PEBI) dan lebih senang berlatih menulis meskipun tidak diperintah guru. Kedua, penerapan pendekatan kontekstual dapat meningkatkan keterampilan menulis murid dari 64 menjadi 75,41.

\section{METODE PENELITIAN}

Jenis penelitian ini adalah penelitian eksperimen. Desain penelitian ini merupakan penelitian preeksperimental designs jenis One-Group Pretes-Posttest Design. Model eksperimen ini melalui tiga langkah yaitu: Memberikan pretest untuk mengukur variabel terikat (hasil belajar) sebelum perlakuan dilakukan, memberikan perlakuan kepada kelas subjek penelitian dengan menerapkan model pembelajaran modelig the way dan memberikan posttest untuk mengukur variabel terikat setelah perlakuan dilakukan.

Populasi dalam penelitian ini adalah seluruh murid SDN 7 Letta Kecamatan Bantaeng Kabupaten Bantaeng sebanyak 141 murid untuk 
keseluruhan. sampel dari penelitian ini seluruh murid kelas III SDN 7 Letta Kecamatan Bantaeng Kabupaten Bantaeng dengan jumlah murid sebanyak 10 orang murid, 5 orang murid laki-laki dan 5 orang murid perempuan.

Variabel Independen (bebas) yaitu Metode Modeling the way suatu metode pengajaran yang dilaksanakan dengan cara guru memberikan skenario suatu sub bahasan untuk didemonstrasikan siswa di depan kelas, sehingga menghasilkan ketangkasan dengan keterampilan atau skill dan profesionalisme. Model pembelajaran Modeling the way yang diterapkan dalam penelitian ini adalah salah satu model pembelajaran dalam pelajaran bahasa Indonesia. Fariabel Dependen (terikat) yaitu Hasil Belajar mengarah pada aspek siswa, dimana siswa yang akan dinilai. Hasil Belajar yang dimaksud dalam penelitian ini adalah kelincahan, ketepatan dan kesesuaian ketika murid menyelesaikan tugas pada tes awal (pretest) dan menyelesaikan tugas pada tes akhir (posttest).

Instrument yang digunakan dalam penelitian ini adalah, tes hasil belajar dan lembar observasi aktivitas murid. Teknik pengumpulan data yang digunakan dalam penelitian ini adalah tes awal dan tes akhir. Untuk menganalisis data yang diperoleh dari hasil penelitian akan digunakan analisis statistik deskriptif dan inferensial.

\section{Hasil dan Pembahasan}

\section{Deskripsi Hasil Pretest Bahasa Indonesia Kelas III SDN 7 Letta Bantaeng Sebelum Diterapkan Metode Modeling the Way}

Sebelum peneliti memberikan proses pembelajaran dengan perlakuan terhadap kelas III SD, peneliti memberikan soal pretest berupa tes tulis. Setiap murid diminta untuk antusias memahami bagian-bagian dan isi teks surat pribadi kemudian murid diminta menulis kembali seperti tema menyusun paragraf tersebut. dengan menggunakan bahasa sendiri. Pretest ini dilakukan untuk mengetahui kemampuan awal murid yakni menyusun paragraf.

Data hasil pretest yang diperoleh dari kelas III SDN 7 Letta Bantaeng dapat diketahui sebagai berikut:

Tabel 4.2 Skor Nilai Pretest

\begin{tabular}{|c|l|c|}
\hline No. & \multicolumn{1}{|c|}{ Nama Murid } & Nilai \\
\hline 1. & Aulia & 60 \\
\hline 2. & Adil & 55 \\
\hline
\end{tabular}




\begin{tabular}{|c|l|c|}
\hline 3. & Fitri & 80 \\
\hline 4. & Ishaq & 69 \\
\hline 5. & Rehan & 53 \\
\hline 6. & Satriani & 42 \\
\hline 7. & Aliaf & 60 \\
\hline 8. & Fahar & 69 \\
\hline 9. & Alia & 75 \\
\hline 10. & Sabra & 45 \\
\hline & JUMLAH & $\mathbf{6 0 8}$ \\
\hline
\end{tabular}

Berdasarkan tabel 4.1 untuk mencari mean (rata-rata) nilai pretest bahasa Indonesia dari murid kelas III SDN 7 Letta Bantaeng dapat dilihat melalui tabel dibawah ini:

Tabel 4.3 Perhitungan untuk mencari mean (rata-rata ) nilai pretest

\begin{tabular}{|c|c|c|}
\hline $\mathbf{X}$ & $\mathbf{F}$ & $\mathbf{X . f}$ \\
\hline 42 & 1 & 42 \\
\hline 45 & 1 & 45 \\
\hline 53 & 1 & 53 \\
\hline 55 & 1 & 55 \\
\hline 60 & 2 & 120 \\
\hline 69 & 2 & 138 \\
\hline 75 & 1 & 75 \\
\hline 80 & 1 & 80 \\
\hline JUMLAH & $\mathbf{1 0}$ & $\mathbf{6 0 8}$ \\
\hline
\end{tabular}

Dari tabel 4.2 di atas dapat diketahui bahwa nilai dari $\sum$ f.x yaitu 608 , sedangkan nilai dari $\mathrm{N}$ itu sendiri adalah 10. Oleh karena itu, dapat diperoleh nilai mean (rata-rata) sebagai berikut:

$$
\begin{aligned}
X & =\frac{\sum f \cdot x}{N} \\
& =\frac{608}{10} \\
& =60,8
\end{aligned}
$$

\section{Deskripsi Hasil Posttest Bahasa Indonesia Kelas III SDN 7 Letta Bantaeng setelah diterapkan Metode Modeling the Way.}

Setelah diberi perlakuan yakni penerapan metode modeling the way terhadap kelas III kemudian selanjutnya diberikan posttest. Kegiatan posttest ini dilakukan untuk melihat hasil pencapaian keterampilan menyusun paragraf murid kelas III. Kegiatan ini serupa dengan kegiatan pembelajaran hanya saja dalam kegiatan ini peneliti tidak lagi memberikan materi pelajaran terkait surat dinas dan surat resmi lainnya, peneliti hanya memberikan contoh dari paragraph susun. Kemudian peneliti akan meminta murid menulis kembali surat tersebut dengan bahasa sendiri.

Adapun data hasil posttest yang diperoleh dari kelas III SDN 7 Letta Bantaeng dapat diketahui sebagai berikut: 
Tabel 4.6 Skor Nilai Posttest

\begin{tabular}{|c|l|c|}
\hline No. & Nama Murid & Nilai Akhir \\
\hline 1. & Aulia & 80 \\
\hline 2. & Adil & 78 \\
\hline 3. & Fitri & 95 \\
\hline 4. & Ishaq & 90 \\
\hline 5. & Rehan & 75 \\
\hline 6. & Satriani & 65 \\
\hline 7. & Aliaf & 80 \\
\hline 8. & Fahar & 90 \\
\hline 9. & Alia & 90 \\
\hline 10. & Sabra & $\mathbf{8 1 7}$ \\
\hline JUMLAH & \\
\hline
\end{tabular}

Untuk mencari mean (rata-rata)

nilai posttest bahasa Indonesia dari murid kelas III SDN 7 Letta Bantaeng dapat dilihat melalui tabel dibawah ini:

Tabel 4.7 Perhitungan untuk Mencari Mean (rata-rata ) Nilai Posttest

\begin{tabular}{|c|c|c|}
\hline $\mathbf{X}$ & $\mathbf{F}$ & $\mathbf{X . f}$ \\
\hline 70 & 1 & 70 \\
\hline 75 & 2 & 150 \\
\hline 78 & 1 & 78 \\
\hline 80 & 1 & 80 \\
\hline 82 & 2 & 164 \\
\hline 90 & 2 & 180 \\
\hline 95 & 1 & 95 \\
\hline JUMLAH & $\mathbf{1 0}$ & $\mathbf{8 1 7}$ \\
\hline
\end{tabular}

Dari tabel 4.7 di atas dapat diketahui bahwa nilai dari $\sum$ f.x yaitu 817, sedangkan nilai dari $\mathrm{N}$ itu sendiri adalah 10. Oleh karena itu, dapat diperoleh nilai mean (rata-rata) sebagai berikut:

$$
\begin{aligned}
X & =\frac{\sum f \cdot x}{N} \\
& =\frac{817}{10} \\
& =81,7
\end{aligned}
$$

Dari hasil perhitungan di atas, maka diperoleh nilai rata-rata dari hasil posttest tes lisan kelas III SDN 7 Letta Bantaeng setelah diterapkan metode modeling the way yaitu 81,7 .

Analisis Berpengaruh Tidakya Penerapan modeling the wayTerhadap Menyusun paragraf Pada Mata Pelajaran Bahasa Indonesia kelas III SDN 7 Letta Bantaeng.

Pada bagian ini dilakukan pengujian terhadap hipotesis penelitian yakni apakah ada atau tidak pengaruhnya metode modeling the way terhadap menyusun paragraf pada mata pelajaran Bahasa Indonesia kelas III Madrasah Ibtidaiyah Muhammadiyah Panampu, maka dalam hal ini teknik yang digunakan untuk menguji hipotesis tersebut adalah teknik statistik inferensial dengan menggunakan uji-t. 
Adapun kriteria pengujian

hipotesis sebagai berikut:

a) Jika $t_{\text {Hitung }}>t_{\text {Tabel }}$ maka $H_{0}$ ditolak dan $\mathrm{H}_{1}$ diterima, artinya penerapan modeling the way berpengaruh terhadap hasil menyusun paragraf murid.

b) jika $t_{\text {Hitung }}<t_{\text {Tabel }}$ maka $\mathrm{H}_{0}$ diterima dan $\mathrm{H}_{1}$ ditolak, artinya penerapan modeling the way tidak berpengaruh terhadap keterampilan menyusun paragraf murid.

Tabel 4.11 Analisis skor Pre-test dan Post-test

\begin{tabular}{|c|l|c|c|c|c|}
\hline N0. & $\begin{array}{r}\text { Nama } \\
\text { Murid }\end{array}$ & $\begin{array}{c}\text { X1 } \\
\text { (Pre- } \\
\text { test })\end{array}$ & $\begin{array}{c}\mathrm{X} 2 \\
(\text { Post- } \\
\text { test })\end{array}$ & $\begin{array}{c}\mathrm{d}= \\
\mathrm{X} 2\end{array}$ & $\mathrm{~d}^{2}$ \\
\hline 1 & Aulia & 60 & 80 & 20 & 400 \\
\hline 2 & Adil & 55 & 78 & 23 & 529 \\
\hline 3 & Fitri & 80 & 95 & 15 & 225 \\
\hline 4 & Ishaq & 69 & 90 & 21 & 441 \\
\hline 5 & Rehan & 53 & 75 & 22 & 484 \\
\hline 6 & Satriani & 42 & 65 & 23 & 529 \\
\hline 7 & Aliaf & 60 & 80 & 20 & 400 \\
\hline 8 & Fahar & 69 & 90 & 21 & 441 \\
\hline 9 & Alia & 75 & 90 & 15 & 225 \\
\hline 10 & Sabra & 45 & 70 & 25 & 625 \\
\hline & Jumlah & 608 & 813 & 205 & 4299 \\
\hline
\end{tabular}

Langkah-langkah dalam pengujian hipotesis adalah sebagai berikut:

a. Mencari harga "Md" dengan menggunakan rumus:

$$
\begin{aligned}
\mathrm{Md} & =\frac{\sum d}{N} \\
& =\frac{205}{10} \\
& =20,5
\end{aligned}
$$

b. Mencari harga " $\sum \mathrm{X}^{2} \mathrm{~d}$ dengan menggunakan rumus:

$$
\begin{aligned}
\sum \mathrm{X}^{2} \mathrm{~d} & =\sum \mathrm{d}^{2}-\frac{\left(\sum d\right)^{2}}{N} \\
& =4299- \\
\frac{(205)^{2}}{10} & \\
& =4299- \\
4202.5 & \\
& =96,5
\end{aligned}
$$

c. Menentukan harga $t_{\text {Hitung }}$ dengan menggunakan rumus:

$$
\begin{aligned}
& \mathrm{t}=\frac{M d}{\sqrt{\frac{\sum x^{2} d}{N(N-1)}}} \\
& \mathrm{t}=\frac{20,5}{\sqrt{\frac{96,5}{10(10-1)}}} \\
& \mathrm{t}=\frac{20,5}{\sqrt{\frac{96,5}{90}}} \\
& \mathrm{t}=\frac{20,5}{\sqrt{1,073}} \\
& \mathrm{t}=\frac{20,5}{1,036} \\
& \mathrm{t}=19,79755
\end{aligned}
$$

d. Menentukan harga $t_{\text {tabel }}$

Untuk mencari ttabel, peneliti menggunakan tabel distribusi $t$ dengan 
taraf signifikan $\alpha=0,05$ dan $\mathrm{db}=\mathrm{n}-1=$ $10-1=9$, maka diperoleh $\mathrm{t}_{0,05}=2,262$.

Setelah diperoleh thitung $=$ 19,79755 dan $t_{\text {tabel }}=2,262$, maka diperoleh $t_{\text {hitung }}>t_{\text {tabel }}$ yaitu 19,79755 < 2,262, sehingga dapat disimpulkan $\mathrm{H}_{0}$ ditolak $\mathrm{H}_{1}$ diterima. Ini berarti bahwa penerapan metode modeling the way berpengaruh Terhadap menyusun paragraf pada mata pelajaran bahasa Indonesia kelas III SDN 7 Letta.

\section{KESIMPULAN DAN SARAN}

Berdasarkan hasil penelitian dan pembahasan tersebut dapat disimpulkan bahwa secara umum hasil belajar murid kelas III SDN 7 Letta sebelum diterapkan metode modeling the way terhadap menyusun paragraf pada mata pelajaran Bahasa Indonesia dikategorikan rendah. Hal ini ditunjukkan pada perolehan persentase hasil belajar siswa dengan dikategorikan sangat rendah terdapat 4 murid yaitu $40 \%$, rendah terdapat 4 murid atau 40\%, sedang terdapat 1 murid atau 10\%, tinggi terdapat 1 murid atau $10 \%$ dan sangat tinggi berada pada persentase $0,00 \%$.

Setelah diterapkan metode modeling the way terhadap menyusun paragraf pada mata pelajaran Bahasa Indonesia, Hasil Belajar siswa kelas III
SDN 7 Letta meningkat. Hal ini ditunjukkan pada perolehan persentase hasil belajar dengan kategori sangat tinggi terdapat 3 murid pada persentase $30 \%$, kategori tinggi terdapat 3 murid pada persentase 30\%, kategori sedang terdapat 4 murid atau persentase $40 \%$, rendah dan sangat rendah berada pada persentase $0,00 \%$..

Berdasarkan uji hipotesis yang telah dilakukan dapat disimpulkan bahwa penerapan Metode modeling the way berpengaruh terhadap menyusun paragraf pada mata pelajaran Bahasa Indonesia, hasil belajar siswa kelas III SDN 7 Letta setelah diperoleh $t_{\text {hitung }}=$ 19,79755 dan $t_{\text {tabel }}=2,262$, maka diperoleh $t_{\text {hitung }}<t_{\text {tabel }}$ atau 19,79755 < 2,086 .

Berdasarkan rumusan masalah penelitian, hipotesis penelitian, dan pembahasan hasil penelitian yang telah dilakukan, maka saran yang dapat dikemukakan oleh peneliti adalah sebagai berikut:

Untuk menggunakan Metode modeling the way sebaiknya guru mempertimbangkan terlebih dahulu alokasi waktu yang diperlukan agar tujuan pembelajaran yang diharapkan dapat tercapai. (1) Metode modeling the way dapat digunakan untuk memotivasi siswa agar lebih aktif dalam kegiatan 
belajar mengajar dan lebih percaya diri serta antusias dalam mengasah keterampilan-keterampilan yang dimiliki siswa itu sendiri. (2) Bagi peneliti selanjutnya yang akan melakukan penelitian serupa, penelitian ini hanya melibatkan 10 orang sampel. Diharapkan melakukan penelitian dengan sampel yang lebih banyak. Hal ini belum memberikan gambaran akurat tentang pengaruh Metode modeling the way.

\section{UCAPAN TERIMA KASIH}

Rasa hormat dan Ucapan terima kasih disampaikan kepada SDN 7 Letta Bantaeng atas kerjasamanya melakukan penelitian selama dua bulan mulai 23 April sampai 9 Juni 2018. Dan terima kasih kepada semua pihak yang telah membantu selama penelitian ini dilakukan.

\section{DAFTAR PUSTAKA}

Andang, Ismail. 2009. Education Games Panduan Praktis Permainan yang menjadi Anak Anda Cerdas, Kreatif dan Shaleh

Azra, Azyumadi. 2002. Pendidikan Multikultural: Membangun Kembali Indonesia Bhineka Tunggal Ika. Makalah Disampaikan dalam Symposium Internasional Antropologi Indonesia ke 3. Denpasar: Kajian Budaya UNUD
Budiyanto.

Pendidikan Kewarganegaraan. Yogyakarta : UNY Press. 2004

Cogan, J.J: Howaya, Rk.K: (1999) The Foundation of Education. New York: Prentice hall, Inc

Depdikbud. 1975. Pedoman Umum Pembentukan Istilah. Jakarta

Depdiknas. 2006. Kurikulum Tingkat Satuan Pendidikan (KTSP). Jakarta:Depertemen Pendidikan Nasional

Djahiri, A. Kosasih. 1995. Dasar Umum Metodologi Pengajaran Pendidikan Nilai Moral. Bandung: Lab. Pengajaran PMP-IKIP Bandung

Endang Zaelani Zukarya, dkk. 2000. Pendidikan Kewarganegaraan untuk Perguruan Tinggi. Yogyakarta: Paradigma.

Kerr, D. 1999 Re;examining Citizenship Education: The Case Of England. Slough:NFER

Mayke S. Tedjasaputra. 2001. Bermain, Mainan dan Permainan untuk Pendidikan Anak Usia Dini. Jakarta:Grasindo

Sapriya. (2011). Pembelajaran IPS. Bandung: Remaja Rosda Karya

Semiawan, Conny R. Prof. Dr. 2008. Belajar dan Pembelajaran Prasekolah dan Sekolah Dasar. Jakarta:PT Index

Soemantri. (2001). Menggagas Pembelajaran Pendidikan. Bandung: Remaja Rosda Karya

Sudjana. (2003). Dasar-Dasar Proses Bekajar Mengajar, Bandung: Sinar Baru 
Sunarso, dkk. Materi dan Pembelajaran Pkn SD. Jakarta: Universitas Terbuka. 2006

Winarno. Paradigma Baru Pendidikan Kewarganegaraan. Jakarta: Bumi Aksara, 2008

Winataputra, Udin, 2001. Apa dan Bagaimana Pendidikan Kewarganegaraan. Sawangan Depok

Zamroni (Tim ICCE). Paradigma Pendidikan Masa Depan. Yogyakarya:BIGRAF Publishing 